\title{
Occupational Exposure Assessment to Gasoline Vapours under Various Conditions at Public Gasoline Stations
}

\author{
By Ahmed Rashid Alyami*
}

\begin{abstract}
Exposure of petrol station attendants to gasoline vapours during the refuelling of vehicles has raised health concerns, especially in countries with warmer climates. This is due primarily to increased gasoline vaporization because of predominantly higher ambient temperatures and the increased risk of inhaling more vapours compared to temperate countries. Such a debate has been highlighted in newspapers, scientific studies, and by the workers themselves. Exposures during extended work shifts (e.g., 12 hours) in the absence of vapour recovery systems and with gasoline containing higher percentage concentrations of toxic substances have not been adequately addressed in the scientific literature. The study assessed the exposures of 41 petrol station attendants via passive, active, and direct reading methods at 12 petrol stations of both high and low sales volumes in the Eastern Province of Saudi Arabia. The effects of the quantity of gasoline sold, the locations of the stations, weather variations (e.g., wind speed, temperature, and humidity) were tested. A custom-made mini-weather station and modified thermometer were utilized to closely monitor sampling weather conditions. A Forward-Looking InfraRed (FLIR) thermal image camera was used to visualize the size and movement behaviour of the vapour plumes during personal monitoring.
\end{abstract}

Keywords: Assessment, Exposure, Gasoline, Occupational health, Petrol station.

\section{Introduction}

\section{Saudi Arabian Petrol Stations}

Petrol stations in Saudi Arabia are full-service stations where all fuel pumping processes are performed by station attendants. The occupational scenario of exposure to gasoline vapours by the station attendants in Saudi Arabia differs to some extent from that in Europe and the United States. Some of the differences include high ambient temperatures (e.g., $38-45^{\circ} \mathrm{C}$ ) during the summer, fullservice stations, no vapour recovery systems, longer working shifts, and different concentrations of gasoline components. The majority of the attendants work 10 to 12 hour shifts performing the same gasoline dispensing activities while remaining in the same area throughout their shifts.

Studies in other countries have recorded health symptoms reported by petrol station attendants such as headache, fatigue, and throat irritation that are thought to be related to exposure to gasoline and its components (Tunsaringkarn et

\footnotetext{
${ }^{*}$ Senior Industrial Hygienist, Saudi Arabia.
} 
al., 2012; ATSDR, 2014). The health symptoms reported could be regarded by occupational health practitioners and researchers as an indication that those workers might be overexposed to harmful gasoline constituents. Questions about exposure of petrol station attendants to gasoline and concerns about health effects have been raised by the public in newspaper articles in Saudi Arabia.

According to Sharayah, "public concern about the risks to health of petrol station attendants in Saudi Arabia needs to be addressed via a thorough exposure investigation by competent occupational health practitioners." To meet this need, at least in part, the current study was undertaken to review the literature pertaining mostly to gasoline exposures at full-service stations internationally and to design and implement a study of exposure assessment. Based on the reviewed literature; BTEX and the fuel additive methyl-tertiary butyl ether (MTBE) were found to have been assessed in the majority of the gasoline occupational exposure assessment studies. Therefore, these components have been included in the field exposure assessments undertaken in this study.

\section{Overview of the Weather Conditions}

In Saudi Arabia's Eastern Region (ER), where this work was carried out, ambient temperature can reach upward of 40 degrees centigrade $\left(40^{\circ} \mathrm{C}\right)$. The monthly average temperature in the summer is around $42^{\circ} \mathrm{C}$ (May-October) while in the winter it is $26^{\circ} \mathrm{C}$ (November-April). The highest temperatures occur during the months of June, July, August, and September (Weather Online Ltd., 2014).

Figure 1 illustrates the variation in ambient temperatures around the year in the ER.

Figure 1. Monthly Weather Temperature Variations during the Year

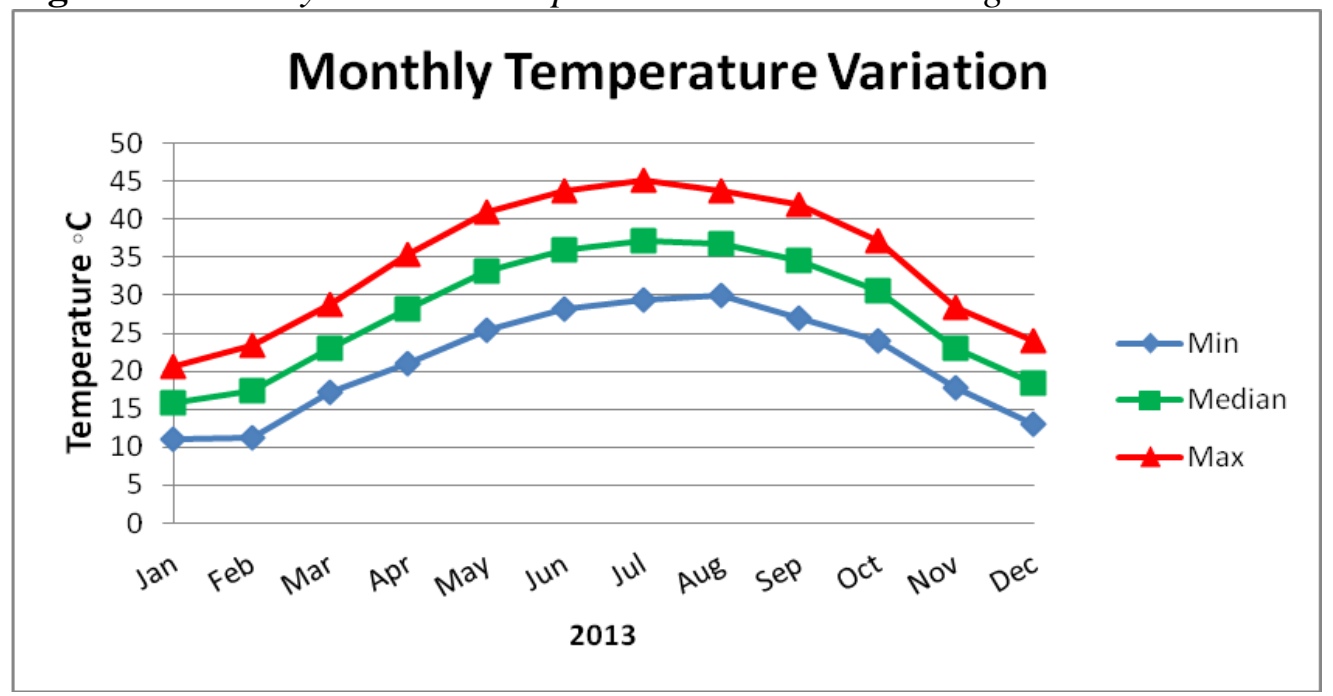

Source: Weather Online Ltd., 2014. 
The ER is influenced by the Arabian Gulf weather conditions (Al-Garni et al., 1999). The wind direction blows predominantly from the northwest (NW) and it is stronger during the winter months (Khonkar, 2009). The estimated wind speed yearly average is 4.4 meters per second $\left(\mathrm{m} . \mathrm{s}^{-1}\right)$ with a range from 3.6 to $5.1 \mathrm{~m} . \mathrm{s}^{-1}$ (Weather Online Ltd., 2014).

Influence of Ambient Temperature and Station Locations on Risk of Exposure to Gasoline Vapours

Studies (Pandya et al., 1975; Periago et al., 1997; Batterman et al., 2005; Kountouriotis et al., 2014) have indicated that the exposure risk of petrol station attendants is likely higher due to elevated ambient temperatures and the increased volatilization of the gasoline, especially in tropical countries. In such countries, filling station workers are likely to inhale more gasoline vapours than in other countries with average ambient temperatures below $30^{\circ} \mathrm{C}$. This is applicable for increasing the risk of exposure to fuel vapours at petrol stations in Saudi Arabia, particularly during the hot weather conditions.

The location of the petrol stations is also an important factor in determining exposure risks, particularly for those petrol stations close to highways or busy traffic. A gasoline vapour exposure study of petrol station attendants compared exposure levels to benzene at two stations located near high traffic roads and in suburban areas with low traffic roads in the cities of Torino and Biella in northwestern Italy. The study concluded that stations near high traffic roads had 22\% higher exposure concentrations (Bono et al., 2003).

\section{Materials and Methodology}

Work was carried out in Dammam and al-Khobar of the Easter Province of Saudi Arabia, which are examples of large and busy metropolitan cities in the country. Therefore, they were considered optimum for the studies due to the availability of the various factors under study. The study's focus was the exposure assessment, using active, passive, and direct reading methods, to airborne gasoline vapours and its most toxic components (i.e., BTEX) and the anti-knocking oxygenated additive MTBE. Such components have the lowest exposure limits set by many organizations (e.g., by US OSHA, 2006; ACGIH, 2015; HSE, 2011; DFG, 2014). Benzene can be considered as the single component of greatest concern because of its confirmed carcinogenicity. The exposure assessments were collected during the summer and winter with ambient temperatures ranging from 18 to $37^{\circ} \mathrm{C}$ (Mode: $18^{\circ} \mathrm{C}$ ), with a mean relative humidity of $33 \%$ and wind speed average of $1.90 \mathrm{~m} . \mathrm{s}^{-1}$. In contrast, during the summer temperatures ranged between 26 to $41^{\circ} \mathrm{C}$ (Mode: $40^{\circ} \mathrm{C}$ ), with relative humidity of $13 \%$, with a wind speed average of $1.6 \mathrm{~m} . \mathrm{s}^{-1}$. A miniportable weather measurement station was custom made to closely and accurately monitor the ambient weather variables. 
Weather factors of ambient air temperature, relative humidity, and wind speed were measured per hour intervals using the portable mini-weather station (

Figure 2). The unit was placed near the attendants' working locations at a height of 1.5 meters. The unit consists of an ambient weather sensor (Weather Hawk 5.10), 12-volt battery pack, and a Campbell Scientific CR8500 data logger, all fitted in a 5 pound (lb) fiberglass box. The sensor and data logger were periodically (semi-annually) taken to the Campbell Scientific qualified representative in Dhahran, Saudi Arabia for calibration and the maintenance service.

\section{Figure 2. Custom Made Mini-weather Station}

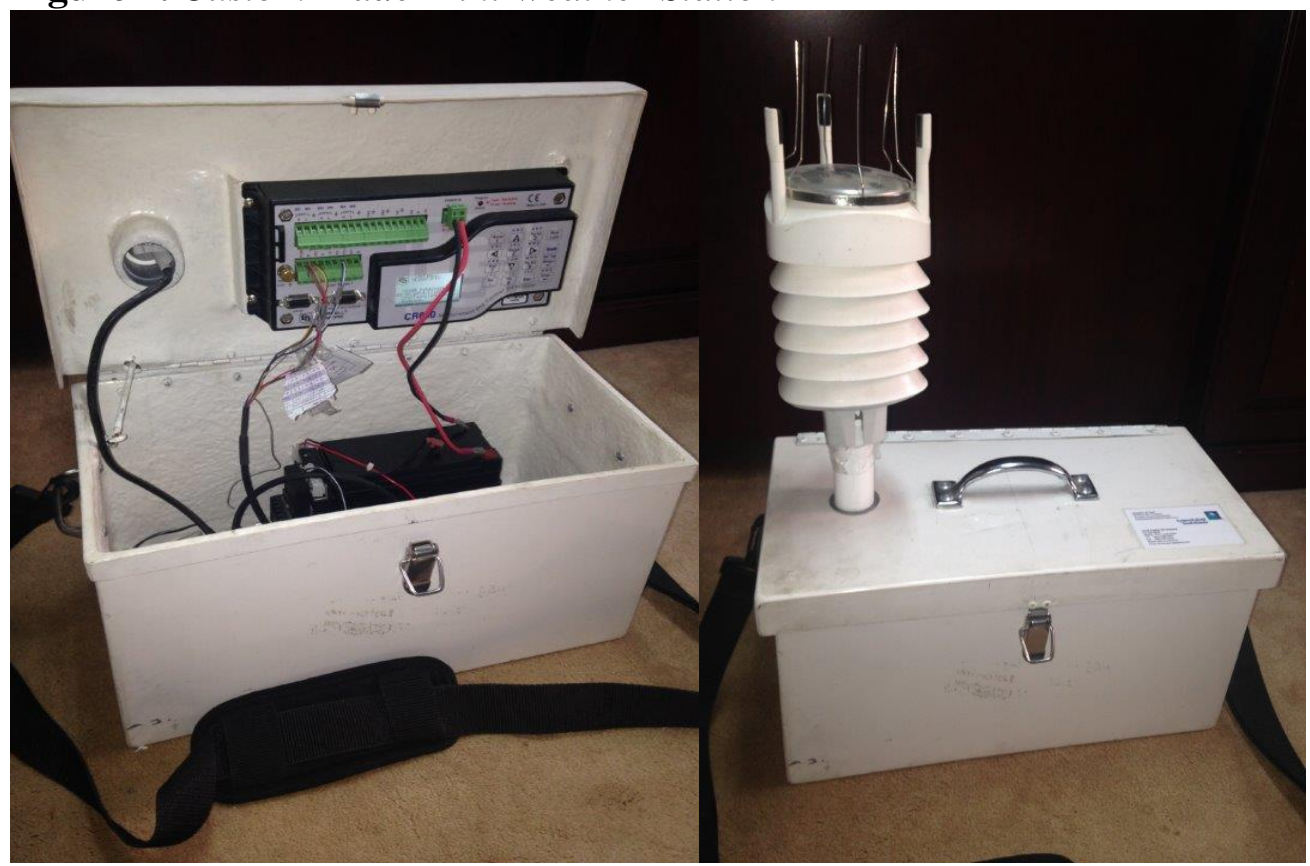

The work was carried out at 12 petrol stations; none were fitted with gasoline vapour recovery systems. Category considerations of high sale volume $(>15,000 \mathrm{~L} /$ day $)$ and low sale volume $(<15,000 \mathrm{~L} /$ day $)$, near heavy traffic or highway, and surrounded (enclosed) by buildings were applied. Depending on the location of the station, a scale of 0-2 was assigned. The number 0 was assigned to stations that are in open areas and neither near highways nor surrounded by buildings; the number 1 was assigned to stations that are either close to a highway or surrounded by buildings; and the number 2 was assigned to stations surrounded by buildings and are near a highway. These classification numbers were utilized for the exposure levels and the location correlation analysis and to test any influence on the personal exposure levels.

The quantity of gasoline dispensed per worker was calculated by averaging the amount of gasoline sold during the shift per the number of workers in the same shift. The personal passive exposure samples were collected for full shifts of 10 to 12 hours or in some cases, at least $80 \%$ of the shift. All tested petrol stations operate for 24-hours. Samples were taken only during day shifts (i.e., 
the worst case scenario) due to the higher gasoline volumes dispensed compared to night shifts.

A total of 41 male petrol station attendants and four control subjects were sampled. All workers were expatriates predominantly from different parts of Asia including India, Pakistan, Bangladesh, Nepal, and the Philippines with ages ranging between 20 and 45 years. The control participants were supervisors who spent their shifts inside offices and away from the gasoline pumps.

The OSHA ID 7 sampling method for organic vapours extracted via carbon disulfide $\left(\mathrm{CS}_{2}\right)$ and analysed via gas chromatography equipped with flame ionization detectors was utilized.

Table 1 illustrates statistical precision information reported by the laboratory for the diffusive samplers.

Table 1. Laboratory Reported Diffusive Sampler Analytical Information

\begin{tabular}{llll}
\hline Analyte & $\begin{array}{l}\text { Flow Rate } \\
(\mathrm{cc} / \mathrm{min})\end{array}$ & $\begin{array}{l}\text { Reporting Limit } \\
(\mu \mathrm{g})\end{array}$ & $\begin{array}{l}\text { Recovery \% } \\
\text { Benzene }\end{array}$ \\
Toluene & 16 & 1 & 95.80 \\
Ethylbenzene & 14.5 & 3 & 95.55 \\
Xylene & 12.9 & 3 & 96.35 \\
MTBE & 12.8 & 6 & 94.20 \\
\hline
\end{tabular}

"Not enough data points.

The diffusive badge SKC 575-001 was used for both personal and area monitoring. Fifty personal and twenty-five area passive samples were collected. Additionally, four passive personal samples were collected from the control subjects.

Ten personal active air samples and one area active air sample were collected on coconut shell charcoal tubes $(100 \mathrm{mg} / 50 \mathrm{mg})$ connected to the SKC Model 222 low flow (50-200 ml. $\mathrm{min}^{-1}$ ) pumps. The types and number of samplers are listed in Table 2. The active air sampling pumps were calibrated before and after sampling and the average flow rate was used for calculation purposes. The air flow rate was set to $200 \mathrm{ml} . \mathrm{min}^{-1}$. Both types of collecting media used have been validated by US OSHA (OSHA, 2008). The air samplers were attached to the workers' collars near the breathing zones (six to nine inches from the nose) (Huey, 1996).

Table 2. Total Sample Numbers and Types

\begin{tabular}{llll|lll}
\hline & Personal & & & Area & \\
& & & Control & \multicolumn{2}{l}{ Control } \\
Benzene & Active & Passive & & Active & Passive & \\
Toluene & 10 & 50 & 4 & 1 & 25 & 1 \\
Ethylbenzene & 10 & 50 & 4 & 1 & 25 & 1 \\
Xylene & 10 & 50 & 4 & 1 & 25 & 1 \\
MTBE & 10 & 50 & 4 & 1 & 25 & 1 \\
\cline { 1 - 2 } & 10 & 50 & 4 & 1 & 25 & 1 \\
\hline
\end{tabular}


The sampling media were collected, cap-sealed, and kept refrigerated at $<5^{\circ} \mathrm{C}$ (Pendergrass, 2003) after each sampled shift. Samples were analysed by the American Industrial Hygiene Association (AIHA) accredited laboratory of Bureau Veritas, located in the USA.

Handheld direct reading photoionising detectors (PID) were used for instant (direct) measurements. MiniRae 2000 and 3000 models were used to measure the gasoline vapour as a total volatile organic compound (TVOC) (Coy et al., 2000; Park et al., 2000). UltraRae 2000, which is benzene specific, provided with a filtering tube, was used to measure benzene in the gasoline vapour. The instruments were calibrated against $100 \mathrm{ppm}$ isobutylene span gas from Rae and Industrial Scientific Corporations. Fresh air calibration was also conducted prior to every measurement. The devices were set to industrial hygiene mode (with STEL and TWA capability) with 30-second measurements and one minute average intervals. All instruments were used with $10.6 \mathrm{eV}$ (electron-Volt) ionization potential (IP) lamps appropriate to detect most VOC components. Measurements were taken mostly at the workers' breathing zone and at the vehicles gasoline tank openings.

A 15-min. benzene occupational exposure measurement was collected using the UltraRae 2000 direct reading PID. The instrument was clipped to the attendant's belt and the air inlet, extended via Tygon tubing, and placed in the workers' breathing zone. The purpose of this measurement was to illustrate the fluctuation of gasoline vapour concentrations in the air during vehicle refuelling and to show how the vapour plumes behave (e.g., passing through the attendants' breathing zone) and the influence of different weather factors (Kountouriotis et al., 2014). Additionally, plume movements were viewed using a forward-looking infrared (FLIR) thermal image system.

The statistical analysis of the data was carried out using pre-programmed MS Excel IHSTAT by John Mulhausen from the AIHA. The correlation coefficient interpretation adopted the Evans Guide for $r$ value as follows (Evans, 1996):

- $0.00-0.19$

- $0.20-0.39$

"Very Weak"

- $0.40-0.59$

"Weak

- $0.60-0.79$

"Moderate"

- $0.80-1.0$

"Strong"

"Very Strong"

\section{Results}

The descriptive statistics for BTEX and MTBE sampling results are shown in Table 3. The geometric mean (GM) of all tested components were within the adopted occupational exposure limits (OEL). The personal passive results for the five sampled components were higher than the controls by $22-78 \%$. The area passive sampling results for benzene, toluene, and MTBE were smaller 
compared to the personal passive results. All results are illustrated in Table 3 and Table 4.

Table 3. Descriptive Statistics for the Personal Passive Sampling Results

\begin{tabular}{llllll}
\hline Parameter & \multicolumn{7}{c}{ Benzene } & \multicolumn{2}{c}{ Toluene } & Ethylbenzene & Xylene & MTBE \\
\hline $\mathrm{N}$ & 50 & \multicolumn{7}{c}{ Personal Passive } & 50 & 50 \\
\hline Mean $(\mathrm{ppm})$ & 0.21 & 0.28 & 0.09 & 0.25 & 1.89 \\
(Controls) & $(0.05)$ & $(0.11)$ & $(0.07)$ & $(0.16)$ & $(0.42)$ \\
\hline Median $(\mathrm{ppm})$ & 0.21 & 0.26 & 0.09 & 0.18 & 1.79 \\
\hline SD $(\mathrm{ppm})$ & 0.13 & 0.15 & 0.02 & 0.39 & 1.14 \\
\hline GM $(\mathrm{ppm})$ & 0.18 & 0.24 & 0.09 & 0.20 & 1.57 \\
\hline GSD & 1.96 & 1.77 & 1.20 & 1.64 & 1.90 \\
\hline
\end{tabular}

Table 4. Descriptive Statistics for the Personal Active Sampling Results

Personal Active (Short Term)

\begin{tabular}{llllll}
\hline Parameter & Benzene & Toluene & Ethylbenzene & Xylene & MTBE \\
\hline $\mathrm{N}$ & 10 & 10 & 10 & 10 & 10 \\
\hline Mean $(\mathrm{ppm})$ & 0.37 & 0.46 & 0.03 & 0.14 & 2.22 \\
\hline Median $(\mathrm{ppm})$ & 0.20 & 0.24 & 0.01 & 0.09 & 1.41 \\
\hline $\mathrm{SD}(\mathrm{ppm})$ & 0.48 & 0.58 & 0.02 & 0.13 & 2.42 \\
\hline $\mathrm{GM}(\mathrm{ppm})$ & 0.21 & 0.27 & 0.02 & 0.09 & 1.37 \\
\hline GSD & 3.01 & 2.92 & 2.08 & 2.33 & 2.82
\end{tabular}

The area samples for the BTEX and MTBE compounds were collected using diffusive samplers similar to those used for personal samples. The results of these samples are shown in

Table 5. The results of the area samples for benzene, toluene, and MTBE were lower than those measured for the personal samples. The ethylbenzene and xylene results were higher for the area samples compared to the personal samples.

Table 5. Descriptive Statistics for the Area Passive Sampling Results

\begin{tabular}{lccccc}
\hline Area Passive & & & & & \\
\hline Parameter & Benzene & Toluene & Ethylbenzene & Xylene & MTBE \\
\hline $\mathrm{N}$ & 26 & 26 & 26 & 26 & 26 \\
\hline Mean (ppm) & 0.06 & 0.15 & 0.13 & 0.27 & 0.40 \\
\hline Median (ppm) & 0.04 & 0.10 & 0.09 & 0.18 & 0.29 \\
\hline SD (ppm) & 0.04 & 0.11 & 0.11 & 0.22 & 0.36 \\
\hline GM (ppm) & 0.05 & 0.12 & 0.10 & 0.22 & 0.30 \\
\hline GSD & 1.89 & 1.80 & 1.99 & 1.787 & 2.23
\end{tabular}


Gasoline vapour in air was measured as VOC using direct reading PID (Coy et al., 2000; Park et al., 2000). Readings ranged from 0.17 ppm to 6.8 $\mathrm{ppm}$. The vapour readings at the vehicle's gasoline tank opening ranged from 300 ppm to more than 1,300 ppm (

Figure 3). Such levels dramatically decrease (i.e., dilution) approximately $92 \%$ at a distance of 0.50 meter, which is the approximate distance between the vehicle's gasoline tank opening and the attendants' breathing zone when refueling. These levels were measured in ambient conditions of $1.2 \mathrm{~m} . \mathrm{s}^{-1}$ wind speed, $35{ }^{\circ} \mathrm{C}$ temperature, and $24 \% \mathrm{RH}$.

Figure 3. Direct Reading Measurement of Gasoline Vapour at Vehicle Gasoline Tank Opening

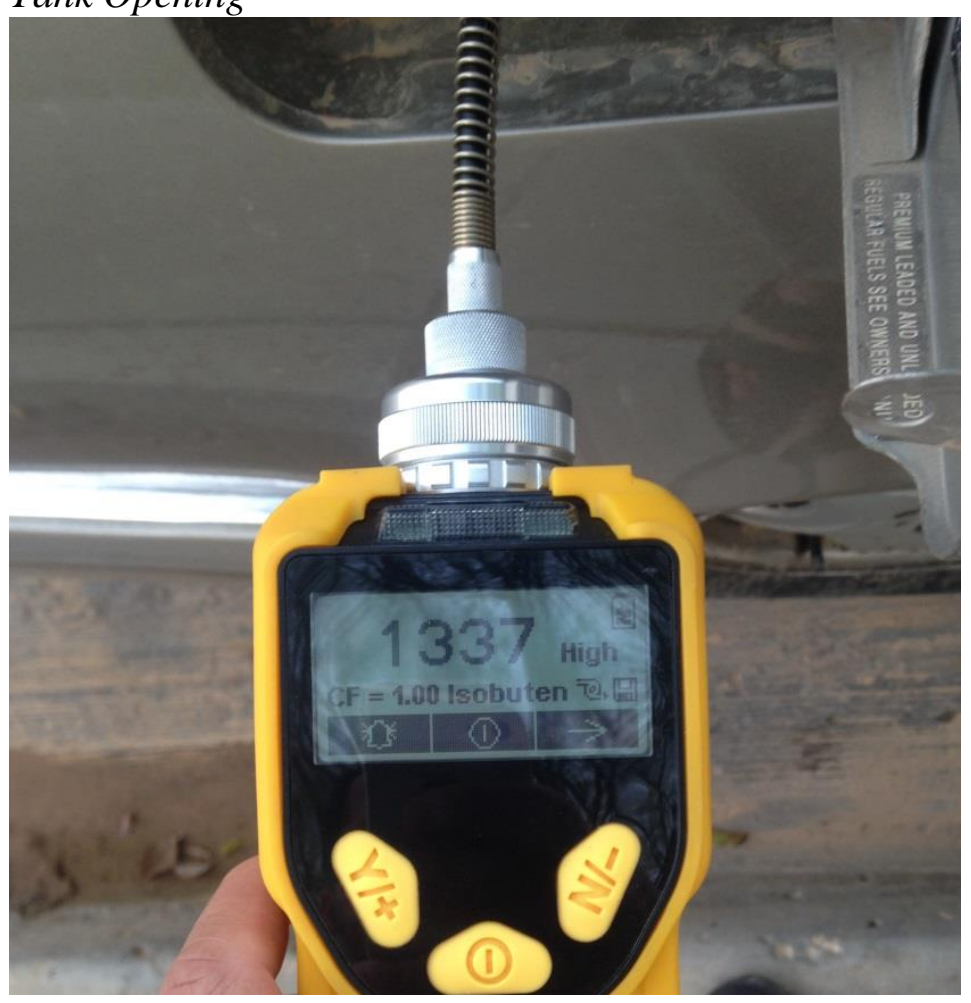

The benzene exposure results were statistically analysed to test their relationships with the various factors, such as, quantity of gasoline sold, ambient air temperatures, relative humidity, wind speed, and station location. These results were refined by calculating the GMs of benzene concentrations for each factor. For example, the GM was calculated for all benzene concentrations collected at an ambient temperature of $39{ }^{\circ} \mathrm{C}$. The results of these relations are illustrated in 
Figure 4 . The quantity of gasoline pumped $(2,453-14,553 \mathrm{~L})$ showed a moderate positive correlation $(r=0.53)$ with the personal exposures to benzene. A moderate negative (inverse) correlation $(r=-0.53)$ was found for the benzene results and wind speed $\left(0.7-4.2 \mathrm{~m} \cdot \mathrm{s}^{-1}\right)$. A very weak positive correlation $(r=0.08)$ was found for the ambient temperature $\left(18-42^{\circ} \mathrm{C}\right)$, and a very weak negative $(r=-0.08)$ correlation was found for the relative humidity (9-59\%). 
Figure 4. Benzene Concentration and Relationship with Various Factors

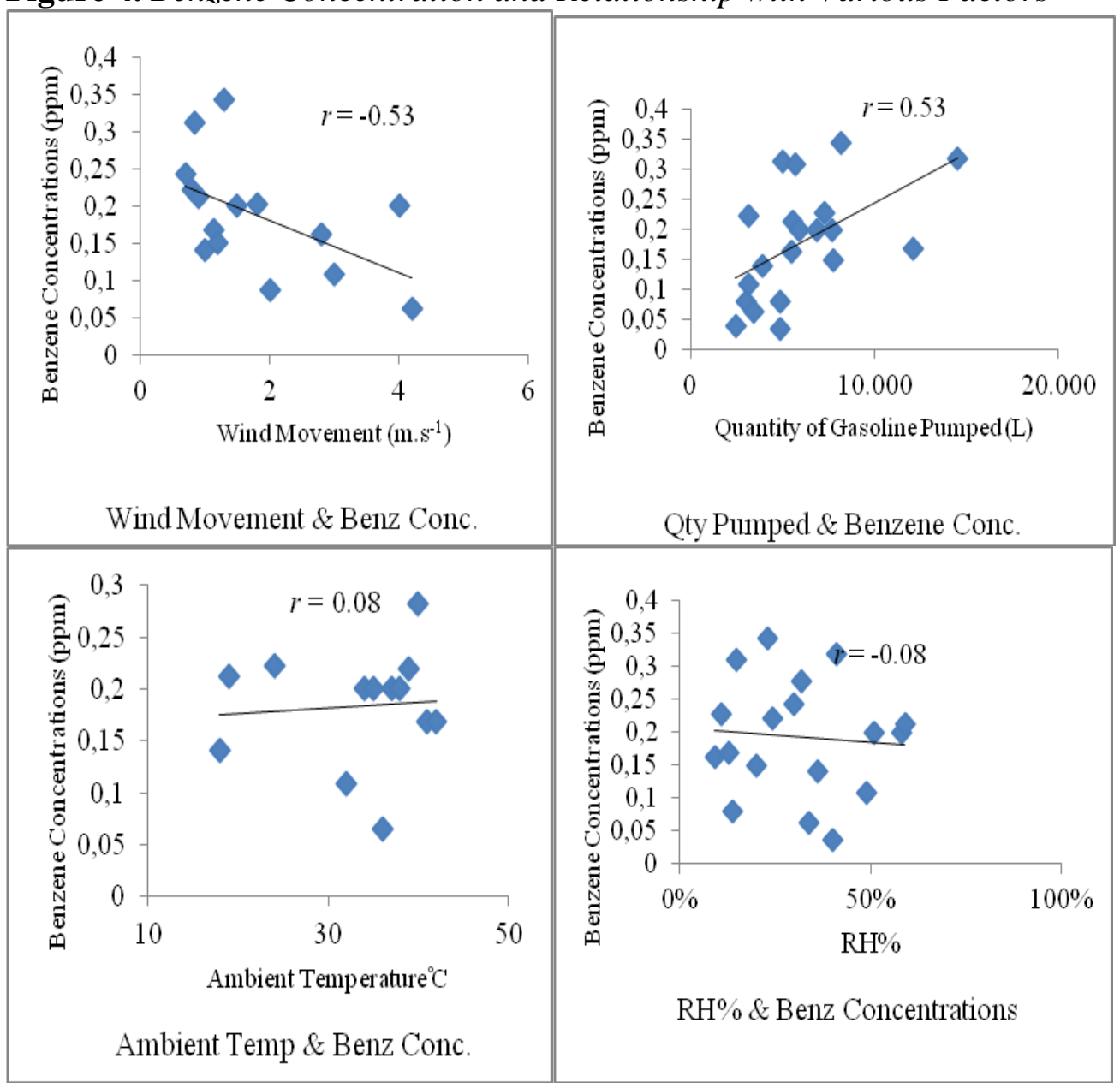

A clear observation of the increased concentrations of benzene with the locations surrounded by buildings and highways was noticed. The GM of each location category was $0.11 \mathrm{ppm}$ for the open area, $0.19 \mathrm{ppm}$ for the surrounded stations by buildings or near a highway, and $0.29 \mathrm{ppm}$ for stations that are both surrounded by buildings and near highways.

A weak negative correlation $(r=-0.25)$ was found for the wind speed and the direct reading, 15-minute trial measurement of benzene. This relationship is illustrated in 
Figure 5. Both wind speed and benzene concentration responses were plotted in the same graph (

Figure 6) to demonstrate their interaction. In this illustration, a trend is showing a slight decrease in the wind speed and an opposite increase peak at the minutes 10:54 AM and 10:58 AM. 
Figure 5. Wind Speed and Benzene Concentration Relationship in a 15 min Air Monitoring

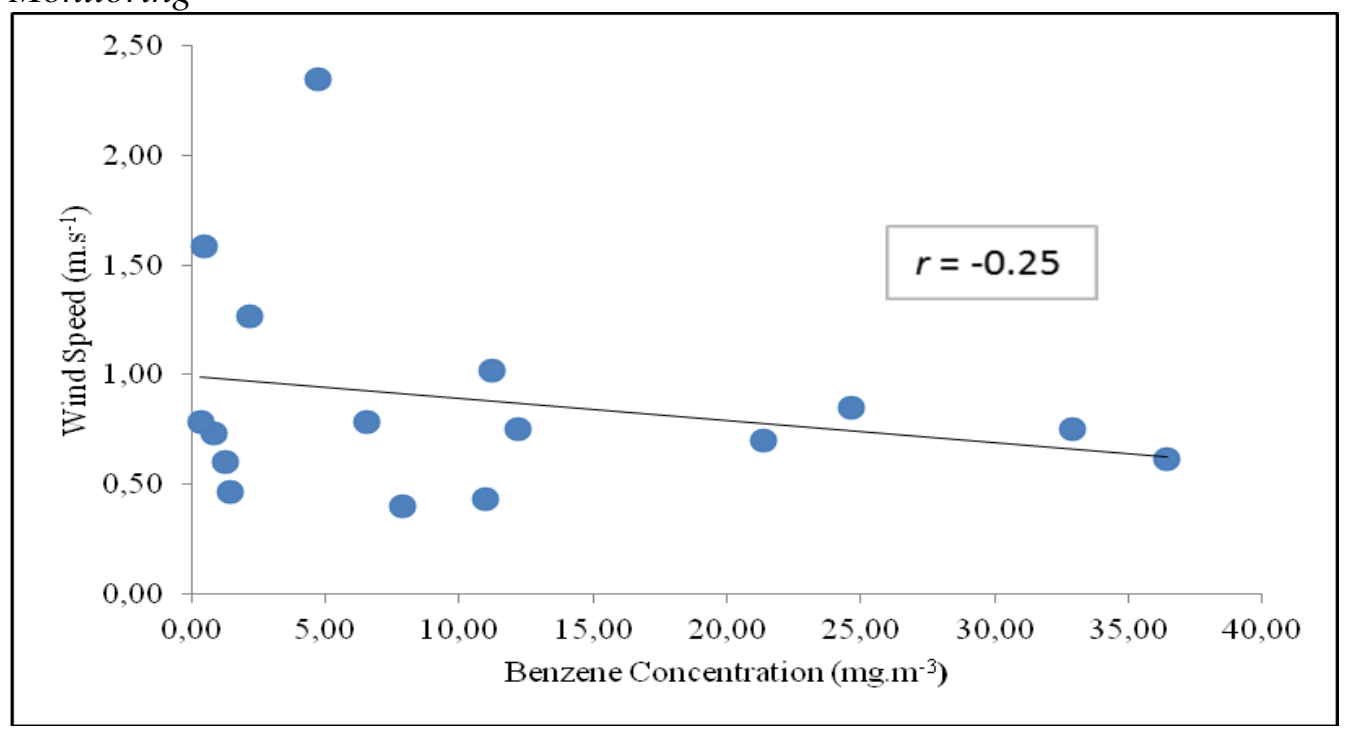

Figure 6. Wind Speed and Benzene Concentration Relationship during $15 \mathrm{~min}$ Monitoring

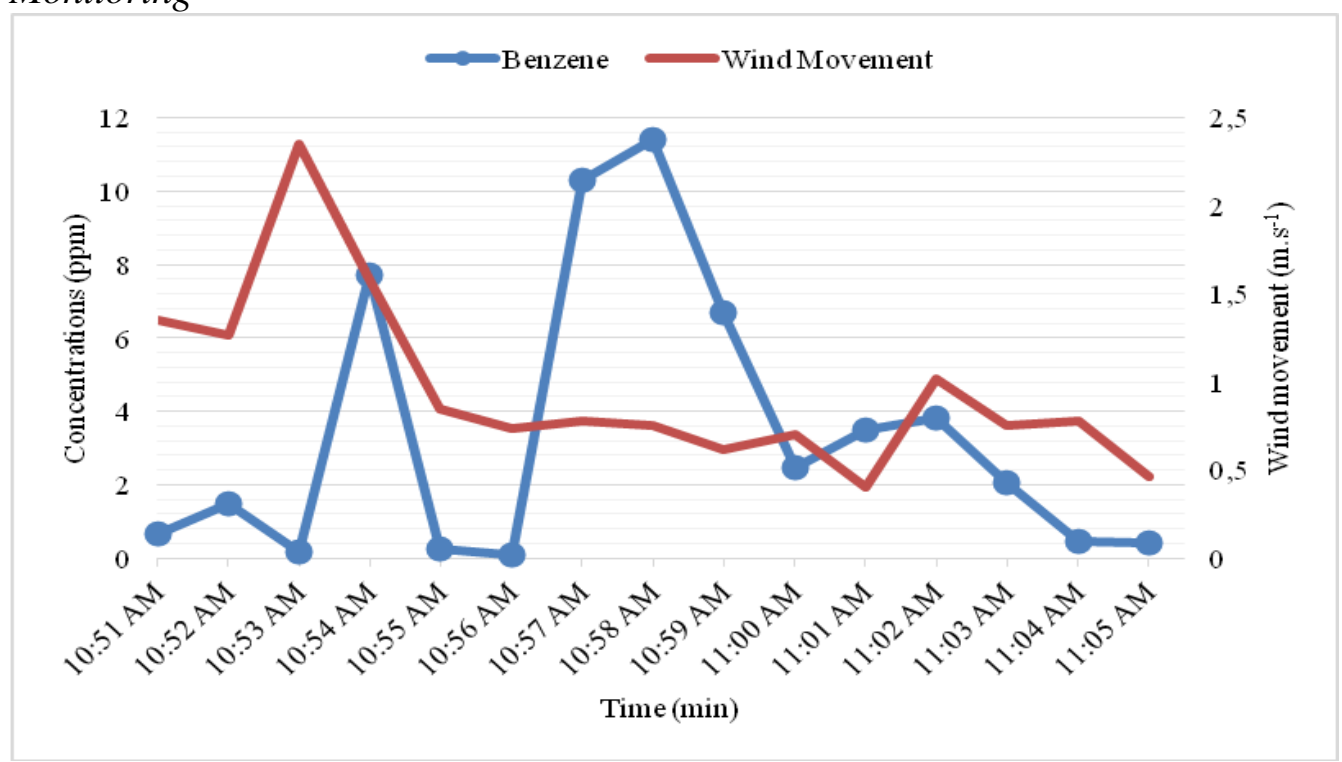

\section{Discussion}

The GMs of the personal passive samples were below the OELs adopted by Saudi Arabia and other international organizations, adjusted for 12-hour shifts (OSHA; ACGIH; HSE; and MAK) as shown in

Table 6. Such values were adjusted for the 12-hour shifts using OSHA adopted equation (1): 
$12 \mathrm{hr} \mathrm{OEL}_{\text {adjusted }}=\frac{\mathbf{8}}{\mathbf{1 2}} \times \mathbf{8} \boldsymbol{h r} \boldsymbol{O E L}$

All results were below $50 \%$ of the OELs reflecting a very low risk for exposures to the tested gasoline vapour chemical components. These values agreed with a historical cohort of station attendants' exposures study carried out in Italy in 1993 (Lagorio et al., 1993).

Table 6. Comparison of the Air Sampling Results to Adjusted 12-hour OELs

\begin{tabular}{llllll}
\hline Chemical & $\begin{array}{l}\text { GM } \\
\text { Results } \\
(\mathrm{ppm})\end{array}$ & $\begin{array}{l}\text { HSE } \\
(\mathrm{ppm})\end{array}$ & $\begin{array}{l}\text { OSHA } \\
(\mathrm{ppm})\end{array}$ & $\begin{array}{l}\text { ACGIH } \\
(\mathrm{ppm})\end{array}$ & $\begin{array}{l}\text { MAK } \\
(\mathrm{ppm})\end{array}$ \\
\hline Benzene & 0.19 & 0.66 & 0.66 & 0.33 & 0.66 \\
\hline Toluene & 0.24 & 33 & 133 & 13.33 & 33 \\
\hline $\begin{array}{l}\text { Ethyl } \\
\text { Benzene }\end{array}$ & 0.09 & 68 & 67 & 13.33 & 13.33 \\
\hline Xylene & 0.20 & 33.33 & 66 & 66 & 66 \\
\hline MTBE & 1.60 & 33 & 33 & 33 & 33 \\
\hline
\end{tabular}

Most of the GMs of the personal passive results agreed with those of the active results. Personal passive results for benzene, toluene and MTBE were 71,46 , and $79 \%$ higher, respectively, than area passive results. The personal passive results for ethylbenzene and xylene were 8 and $44 \%$ lower, respectively, than the area passive results. The GMs of the exposures to BTEX and MTBE for the assessed petrol station attendants were found to be relatively higher than those reported for attendants' exposure levels in Europe and North America (IARC, 2012; Concawe, 2002). Such variation is attributed to influencing factors such as ambient temperature, larger quantity of gasoline pumped per attendant for full service stations, and the locations of the petrol stations.

The effect of the ambient temperature on the exposure increase was minimal as illustrated by the very weak positive correlation with the benzene exposure concentrations. This did not fully concur the positive effects of the ambient temperatures in the increase of exposure as concluded in other studies (Periago et al., 1997; Kountouriotis et al., 2014). Benzene exposures increased proportionately with increased quantity of gasoline dispensed (Kearney and Dunham, 1986). This was shown by the moderate positive correlation coefficient of $r=0.53$. As expected, wind speed decreased airborne benzene concentrations (Kountouriotis et al., 2014). The correlation coefficients were always negative $(r=-0.53$ and -0.25$)$ during the full shift and short term monitoring, respectively. There is no significant correlation between relative humidity and airborne benzene concentrations.

The location of the petrol stations was found to have a strong relationship with the exposure levels which agreed to that concluded by Bono et al. 2003 (Bono et al., 2003). The stations that were closest to heavy traffic and were surrounded by buildings (i.e., Classification 2) had the highest exposure levels as shown in 
Vol. 4, No. 4 Alyami: Occupational Exposure Assessment to Gasoline Vapours...

Figure 7. 
Figure 7. Relationship between the Station Location Categories and Benzene Concentrations

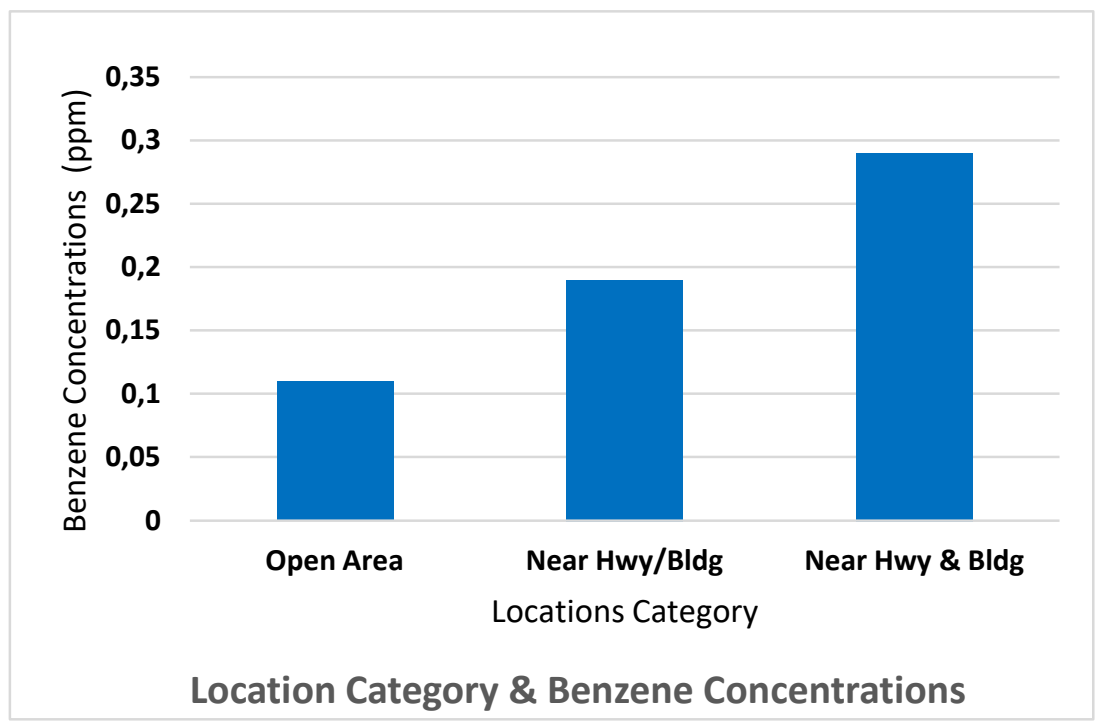

Similarly, the relationship between the quantity of gasoline pumped and the concentrations of benzene in air was clearly noticed as shown in Figure 8.

Figure 8. Relationship between the Quantity of Gasoline Pumped and Benzene Concentrations

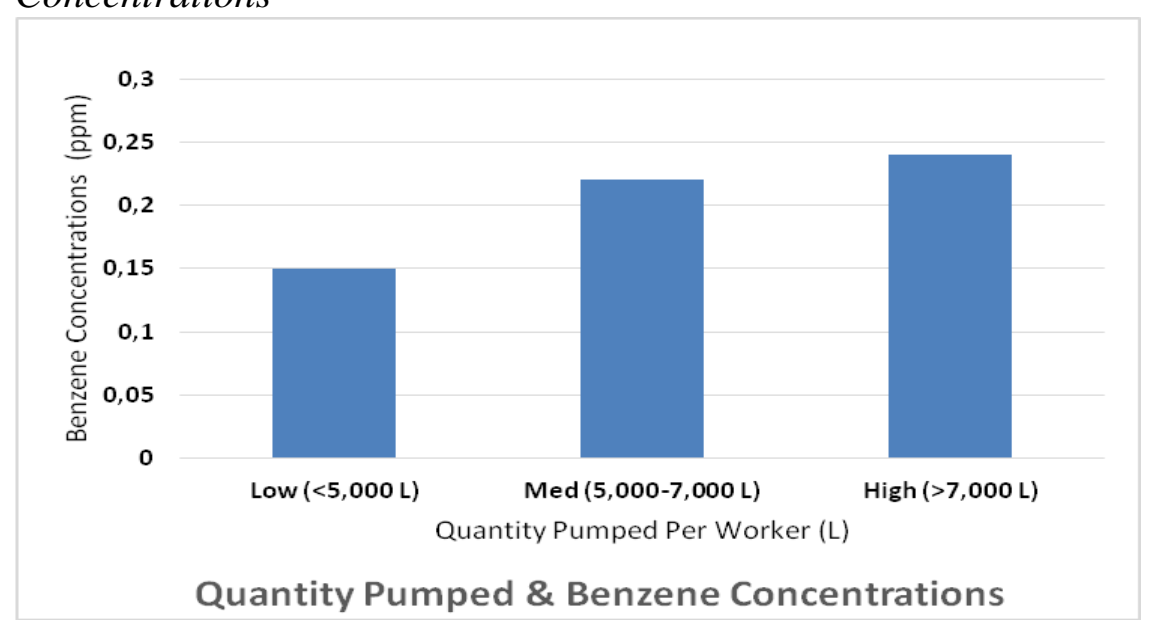

The FLIR recording helped approximating the safe distance at which gasoline vapour concentrations would be reduced ( 
Vol. 4, No. 4 Alyami: Occupational Exposure Assessment to Gasoline Vapours...

Figure 9). The FLIR video suggests that the gasoline vapour plume is largest at the start of refueling and gradually decreases as the gasoline tank is filled and the vapour volume inside the tank is gradually displaced with the gasoline liquid. 
Figure 9. Gasoline Vapour Plume Illustration by FLIR

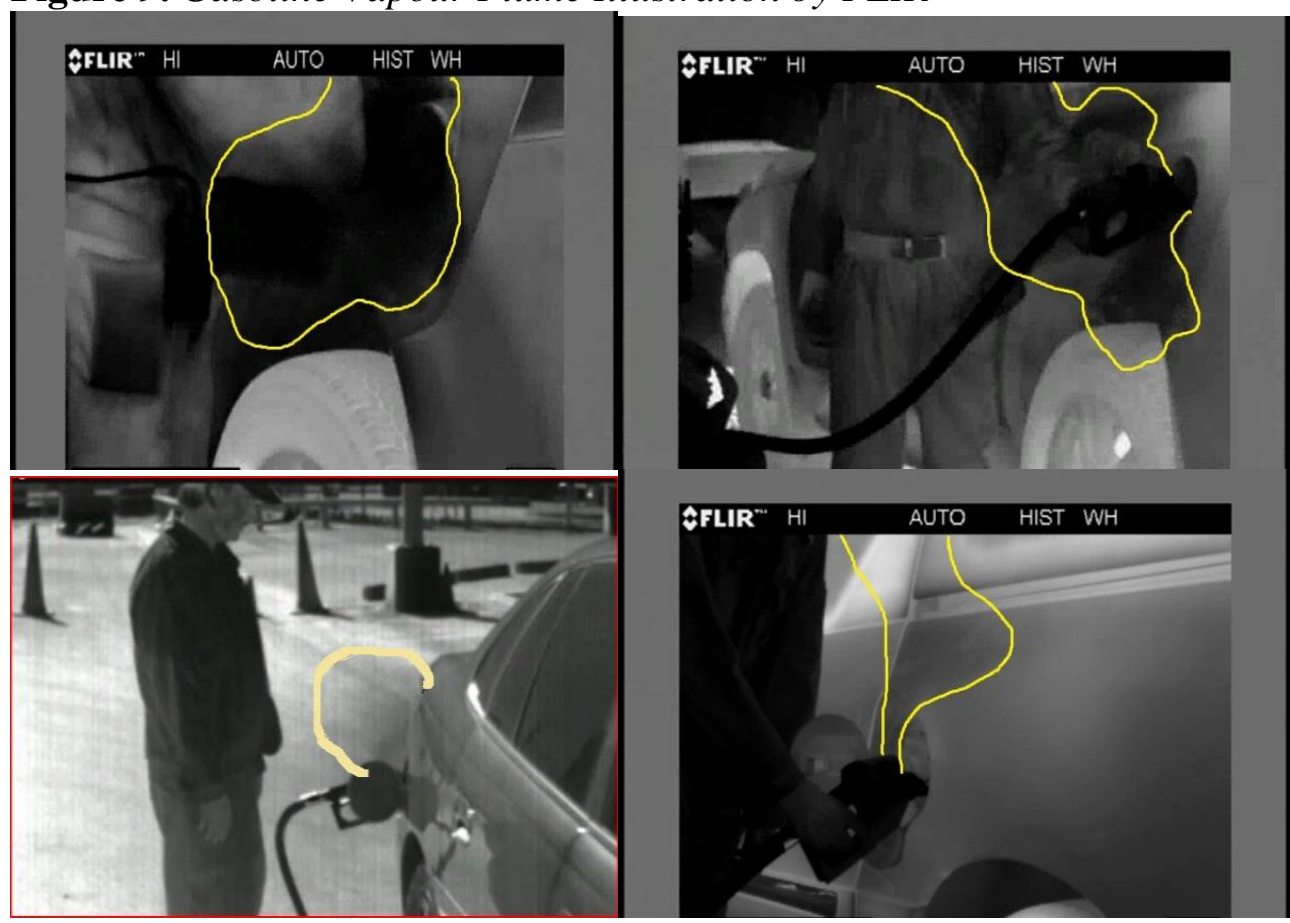

Studies conducted by the Conservation of Clean Air and Water in Europe (Concawe) organization on petrol station attendants in European countries showed an exposure reduction of up to $66 \%$ through the use of gasoline vapour recovery systems (Concawe, 2002). Others studies have reported up to an $80 \%$ reduction in exposures (Cruz-Nunez et al., 2003). Assuming similar recovery efficiency as reported by CONCAWE, the measured exposure concentration in this study could potentially be reduced to the levels shown in

Table 7 by the installation of a gasoline vapour recovery system.

Table 7. Comparison of the GM for the Tested Exposure Results and the Vapour Recovery Retrofitted Stations Tested in Europe (Concawe, 2002)

$$
\text { Tested Exposure Results Theoretical values w/VR* }
$$

\begin{tabular}{lcc} 
& $(\mathrm{ppm})$ & $(\mathrm{ppm})$ \\
\hline Benzene & 0.19 & 0.06 \\
\hline Toluene & 0.25 & 0.08 \\
\hline Ethylbenzene & 0.09 & 0.03 \\
\hline Xylene & 0.20 & 0.06 \\
\hline MTBE & 1.60 & 0.55
\end{tabular}

${ }^{*}$ Vapour Recovery retrofitted stations.

\section{Conclusions and Recommendations}

All five measured toxic compounds (BTEX and MTBE) in the gasoline vapour were found to be in compliance with the currently adopted OELs. The hot summer season very slightly increases the exposure levels for the petrol 
station attendants. The location of the petrol stations was found to be an important factor that can influence the levels of exposure. The relationship was found to be strong between locations near heavy traffic and proximity to buildings. Site selection should then be an important factor to consider further reducing potential occupational exposures to gasoline vapours through natural ventilation and its direct effect on diluting or reducing airborne VOC concentrations. Wind speed and quantity of gasoline dispensed also play significant roles on the exposure levels. The volume of the released vapour from the car gasoline tank is largest at the beginning of the dispensing process at a distance of $\leq 0.30 \mathrm{~m}$. The concentrations of released vapour dramatically decreased at a distance of $\geq$ $0.50 \mathrm{~m}$ away from the tank openings. Theoretically, the gasoline vapour exposure levels can be reduced by $66-80 \%$ by installing vapour recovery systems.

Administrative controls are recommended that include educating and training the petrol station attendants on the exposure health hazards associated with gasoline components, the typical routes of exposure (including dermal), improving the work practices, and exposure avoidance techniques (e.g., standing upwind of the vehicle tank openings).

\section{References}

ACGIH, 2015. TLVs And BEIs Based on the Documentation of the Threshold Limit Values for Chamical Substances and Physical Agents \& Biological Exposure Indices.

Al-Garni, A., Sahin, A. and Farayedhi, A., 1999. Modelling of Weather Characteristics and Wind Power in the Eastern Part of Saudi Arabia. International Journal of Energy Research, 23, pp.805-812.

ATSDR, 2014. Gasoline (Mixture) General Information. Available at: https://www.atsdr. cdc.gov/MHMI/mmg72.pdf.

Batterman, S. A. et al., 2005. Non-methane hydrocarbon emissions from vehicle fuel caps. Atmospheric Environment, 39(10), pp.1855-1867. Available at: http://bit.ly/ 2jSiwMW.

Bono, R. et al., 2003. Ambient Air Levels and Occupational Exposure to Benzene, Toluene, and Xylenes in Northwestern Italy. Journal of Toxicology and Environmental Health, Part A, 66(6), pp.519-531.

Concawe, 2002. Survey of European Gasoline Exposures for the Period 1999-2001.

Coy, J. D. et al., 2000. Field Evaluation of a Portable Photoionization Detector for Assessing Exposure to Solvent Mixtures. AIHAJ - American Industrial Hygiene Association, 61(2), pp.268-274.

Cruz-Nunez, X., Hernandez-Solıs, J. M. and Ruiz-Suarez, L. G., 2003. Evaluation of vapor recovery systems efficiency and personal exposure in service stations in Mexico City. Science of the total environment, 309(1), pp.59-68.

DFG, 2014. Deutsche Forschungsgemeinschaft; List of MAK and BAT Values 2014. In List of MAK and BAT Values 2014. Wiley-VCH Verlag GmbH \& Co. KGaA, p. COVER-XXVII.

Evans, J., 1996. Straightforward Statistics for the Behavioral Sciences, California, USA: Brooks/Cole Publishing Company.

HSE, 2011. EH40/2005 Workplace Exposure Limits., 2nd edition. Available at: http://www.hse.gov.uk/pubns/books/eh40.htm.

Huey, M., 1996. Air Sampling. In B. Plog, J. Niland, and P. Quinlan, eds. Fundamentals 
of Industrial Hygiene. Itasca, Illinois: National Safety Council, pp. 485-499.

IARC, 2012. Chemical Agents and Related Occupations., 100 F.

Kearney, C. A. and Dunham, D. B., 1986. Gasoline vapor exposures at a high volume service station. The American Industrial Hygiene Association Journal, 47(9), pp.535-539.

Khonkar, H., 2009. Complete Survey of Wind Behavior over the Arabian Gulf. Journal of King Abdulaziz University: Marine Sciences, 20, pp.31-47.

Kountouriotis, A., Aleiferis, P. G. and Charalambides, A. G., 2014. Numerical investigation of VOC levels in the area of petrol stations. Science of The Total Environment, 470-471(0), pp.1205-1224.

Lagorio, S. et al., 1993. Exposure Assessment in a Historical Cohort of Filling Station Attendants. International journal of epidemiology, 22 (Supplement 2), pp.S51-S56.

OSHA, 2006. OSHA Annotated Table Z-1, Air Contaminants. Available at: http://bit.ly/ $2 \mathrm{iUJljQ}$.

OSHA, 2008. OSHA Technical Manual., 2012(10/15). Available at: http://bit.ly/2j4q $\mathrm{kXa}$.

Pandya, K. P. et al., 1975. Occupational exposure of petrol pump workers. Annals of Occupational Hygiene, 18(4), pp.363-364. Available at: http://bit.ly/2jSuWnR.

Park, J., Zhang, G. and Zellers, E. T., 2000. Personal monitoring instrument for the selective measurement of multiple orga ..., 8663 (February).

Pendergrass, S., 2003. Hydrocarbon, Aromatic 1501., Fouth Edition.

Periago, j., Zambudio, A. and Prado, C., 1997. Evaluation of environmental levels of aromatic hydrocarbons ingasoline service stations by gas chromatography. Journal of Chromatography, 778, pp.263-268.

Tunsaringkarn, T. et al., 2012. Occupational Exposure of Gasoline Station Workers to BTEX Compounds in Bangkok, Thailand. The International Journal of Occupational and Environmental Medicine, 3, pp.117-125.

Weather Online Ltd., 2014. Dhahran Airport Analysis. Available at: http://bit.ly/2jIc1cN. 
